\title{
Tributo a Mariano Latorre
}

El 10 de noviembre de 1955 dejó de existir en Santiago de Chile, don Mariano Latorre Court, víctima de una antigua afección cardíaca que le había mantenido recluído en reposo en su hogar. La noticia del deceso causó consternación en la docencia y en los círculos culturales que habían venido admirando al notable prosista chileno a través de su continuada obra literaria. Instituciones como el PEN Club, la Sociedad de Escritores, el Círculo de Periodistas, la Sociedad Nacional de Profesores, el Sindicato de Escritores, la Sociedad de Autores Teatrales, la Agrupación de Intelectuales, la Sociedad del Libro Americano, así como el Consejo de Profesores del Liceo Valentín Letelier se reunieron extraordinariamente para dejar constancia del pesar que sentían por la desaparición del estimado escritor y maestro. La Facultad de Filosofía y Educación de la Universidad de Chile, al conocer el fallecimiento del ex catedrático y director del Instituto Pedagógico, dispuso el traslado del extinto a la Casa Central Universitaria y designó a su decano, señor Eugenio Pereira Salas, para despedirlo antes de que el cortejo partiera al cementerio, y al director del Instituto Pedagógico, don Egidio Orellana, para usar de la palabra en los actos de sepultación. El Ministro de Educación, señor Tobías Barros, acompañado del subsecretario, señor René del Villar, presentó las condolencias oficiales del Gobierno a la familia y a la Universidad de Chile.

La personalidad de don Mariano Latorre Court bien se merecía estos honores y demostraciones de pesar por su destacada actuación como educador, crítico, ensayista y novelista de] campo chileno. 
Nacido el 4 de enero de 1886 en Cobquecura, provincia del Maule, pasó los primeros años de su infancia en su pueblo natal, donde la ocupación principal de los habitantes es la pesca, y en las inmediaciones maulinas donde abundan los huasos chilenos.

Es posible que sus primeras impresiones de niño, al observar la vida de los pescadores y marineros, se hubiesen grabado en su mente para siempre. Así pues, se explica su admiración profunda por el campo, el puerto y la cordillera de nuestra nación. ${ }^{I}$

Sus padres, él de origen vasco, La Torre, y ella de ascendencia francesa, le enviaron a cursar humanidades en los $\mathrm{Li}$ ceos de Valparaíso y de Talca y luego a estudiar leyes en la Universidad de Chile. Finalmente ingresó al Instituto Pedagógico, donde en 1926 obtuvo su título de profesor de castellano. De esta etapa de la vida de don Mariano, la escritora argentina Julia García Games nos ha dejado una simpática estampa:

Mariano es hijo de su esfuerzo. Su padre lo hubiera querido abogado, la vida lo hizo maestro y literato. Su espíritu demasiado volandero, no podía concentrarse sobre la abstracción de los códigos o penetrar las consideraciones constitucionales o administrativas. Durante las clases escribía prosas líricas o se apasionaba por la lectura de los discípulos de Zola, que por esos años era la escuela de los novelistas. Buscaba con especial deleite la lectura de Daudet y de Maupassant, y dominado por el entusiasmo, trazaba a su vez las líneas de algunos cuentos y de varias novelas..$^{2}$

La muerte de su padre lo obligó a enfrentarse con la dura realidad de la vida teniendo que dejar sus divagaciones para buscar un medio apropiado que le permitiera subsistir y cultivarse a la vez. Un condiscípulo suyo, Enrique Escala,

1 Mariano Latorre, Vida y obra - Bibliografia - Antologia. New York, Hispanic Institute in the United States, 1944, pág. 11. (Trabajo firmado por Magda Arce).

2 Julia García Games, Cómo los be visto yo, Santiago de Chile, Nascimento, 1930, pág. 131. 
es quien entonces le sugiere que se dedique a la pedagogía agregando con la sinceridad propia de un amigo:

No es una carrera muy consoladora pero está de acuerdo con su temperamento. Tengo la seguridad que hará de usted un excelente profesor de literatura.

El mismo, ha escrito Latorre, me presentó a don $\mathrm{En}_{1}$ rique Rivera, vice-rector, entonces del Instituto Nacional. Dos días después era su ayudante, en la pequeña oficina del viejo liceo tradicional. Nuestra amistad no se trizó, a pesar de que el ayudante no ayudaba mucho en las funciones burocráticas y gastaba, según la expresión de don Enrique Rivera, el papel de la oficina, en novelas de problemático valor. ${ }^{3}$

En su carrera administrativa fue inspector, bibliotecario y maestro de Liceo sirviendo desde 1928 hasta 1949, año en que se jubiló en las cátedras de literatura hispanoamericana y chilena en el Instituto Pedagógico, plantel del cual llegó a ser director. Es de anotar que Latorre reemplaza a don Carlos Mondaca en el desempeño de su cátedra, siendo todavía estudiante y que su nombramiento en propiedad se cursa años después. Al comentar la publicación de Chilenos del mar, don Augusto Santelices, por aquellos años alumno de Latorre, hace una vívida pintura del joven maestro:

Mariano Latorre, alto, balanceándose como un mástil, llegaba siempre apresurado; arriba una mano sujetando los libros bajo el brazo, y la otra retorciendo implacablemente los bigotes color pelo de choclo; abajo las piernas, alejándose hacia los lados y hacia adelante, en unas zancadas, transversales, tragaleguas. Nosotros teníamos la idea de que estaban celosas o divorciadas entre sí, acaso por una cuestión de pantalones, y esta idea se hizo evidencia, cuando un día, al encaramarse una sobre la otra, advertimos que vestía cada una por su cuenta, es decir, llevaba calcetines de distinto color. ${ }^{4}$

Sus labores docentes en el Instituto Pedagógico y en el Liceo Valentín Letelier sólo se vieron interrumpidas cuando, re-

$3 \quad$ Ibid., pág. 132.

4 Augusto Santelices, Sobre: Chilenos del mar, El Mercurio (Santiago de Chile), 10 de noviembre de 1929. 
conociendo sus cualidades de maestro, otros planteles educacionales lo invitaron a dictar cursos. En 1936 el gobierno del Perú lo lleva a la Universidad de San Marcos, en 1938 viaja a Colombia para asistir a los actos conmemorativos del Cuarto Centenario de Bogotá, como huésped oficial del Gobierno para difundir los méritos de los autores chilenos ya consagrados y en 1942 la Universidad de Buenos Aires lo invita con igual propósito a sus prestigiosas aulas. En 1943 dicta un ciclo de conferencias en Bolivia y en 1946 es designado Decano de la Facultad de Filosofía y Educación, cargo que desempeñó hasta asumir la dirección del Instituto Pedagógico. Al jubilarse en 1949, el Gobierno de Chile utilizó los valiosos servicios del señor La. torre designándolo Adicto Cultural en España. Aparte de los honores ya anotados, era miembro académico de la Facultad de Filosofía y Educación de la Universidad de Chile y académico honorario de la Real Academia Española.

La obra literaria de don Mariano Latorre y su labor como crítico y ensayista es demasiado extensa para limitarla al reducido espacio de un artículo. ${ }^{5}$ Omitiendo muchos títulos de interés así como las innumerables ediciones que se han hecho de sus creaciones, se podrian destacar las siguientes:

Cuentos del Maule (1912), Cuna de cóndores (1918), Zurzulita (1920), Ully y otras novelas del sur (1923), Sus mejores cuentos (1925), Collares (1927), La confesión de Tognina (1927), Chilenos del mar (1929), Hombres en la selva (1933), On Panta (1935), Hombres y zorros (1937), Mapu (1942), El choroy de oro (1946), Viento de mallines (1947), Chile, país de rincones (1947), El caracol (1952), La isla de los pájaros (1955).

Entre sus estudios de crítica literaria sobresalen $E l$ pueblo chileno en las novelas de Blest Gana; Ercilla, aventurero de la conquista; Bret Harte y el criollismo; Estudio sobre el teatro chileno y en especial La literatura de Chile, publicada por la

5 Véase: Magda Arce y Sidonia C. Rosenbaum, Mariano Latorre: Bibliografía (estudio que forma parte de la obra consignada en la nota 1 ; contiene un inventario de las composiciones del autor y de la crítica de su obra hasta el año 1943 aproximadamente.

Homero Castillo, Constantes bibliográficas en los cuentos de Mariano Latorre Court, Symposium, Spring, 1955, Vol. IX, I, 126-132. 
Facultad de Filosofía y Letras de la Universidad de Buenos Aires (1941).

En 1936 el señor Latorre obtuvo el Premio Municipal de Novela, en 1937 el Premio Atenea y en 1944 fue agraciado con el Premio Nacional de Literatura, el galardón máximo que Chile confiere a sus escritores.

Los funerales del padre del criollismo chileno tuvieron e] poder de congregar ante su tumba lo más selecto de la intelectualidad chilena, ansiosa de rendirle un homenaje de elogio y reconocimiento. Haciéndose eco de las palabras proféticas que Omer Emeth estampara en el prólogo de Cuna de cóndores, "en mi concepto, Mariano Latorre es un escritor para quien Chile existe verdaderamente", los escritores rivalizaron en destacar los altos quilates de la chilenidad que respiran las páginas de don Mariano.

A nombre del Gobierno, el señor Miguel Angel Vega, Director General de Educación Secundaria, expresó su gratitud y admiración a uno de los más esclarecidos maestros, que honró la docencia chilena y, al mismo tiempo, al escritor que con su pluma exaltó las bellezas de la tierra patria. Al referirse a la obra creadora de Latorre dijo:

La crítica literaria chilena advirtió oportunamente el significado trascendental que traía la prosa de don Mariano Latorre. El incorporó a nuestra literatura la flora y la fauna como realidad viva, describiendo con delectación de artista, desde la mancha de color de nuestros pájaros, hasta las hebras más finas de los líquenes de nuestros bosques. El roturó nuevos surcos en la literatura nacional, señalando el camino del criollismo en el que más tarde lo acompañaron con devoción novelistas y cuentistas de alta alcurnia.

Mariano Latorre pervivirá sin duda en el alma de sus múltiples personajes novelescos y con mayor intensidad en el alma de los que fueron sus alumnos. Será muy difícil olvidar al charlador ameno, incisivo a veces, pero siempre bien intencionado, el gracejo de su palabra y la bonhomia de su espiritu que acaso por haber vivido intensamente comprendió mejor las zozobras e ideales de la juventud. 6

6 Solemne manifestación de pesar constituyeron los funerales del escritor $M a-$ riano Latorre C., El Mercurio (Santiago de Chile), 12 de noviembre de 1955. 
En representación de la Sociedad de Escritores, el conocido novelista Manuel Rojus, se refirió a la vida de Latorre como "una existencia dedicada a una absorbente y exigente pasión espiritual: la literatura, una pasión que empezó en su adolescencia y duró hasta el instante mismo de su muerte". Analizó el significado de la pasión por la literatura, cuya retribución viene después de la muerte, el eterno recuerdo o el eterno olvido. A Mariano no le importó nunca. Hay apasionados por la pasión misma y apasionados por lo que puede traer la pasión. Creemos que Latorre fue de los primeros. "Déjame amarte, y después de mi muerte, haz de mí lo que quieras".

La nota más sobresaliente de las despedidas postreras al colega y amigo, la puso el destacado poeta chileno Pablo Neruda leyendo un poema en prosa cuya hermosura constituye un documento literario que no debe pasar ignorado y que por ello reproducimos en su totalidad:

Este día frío en medio del verano es como su partida, como su desaparición repentina, en medio del regocijo multiplicado de su obra.

Quiero dedicarle un vuelo del queltehue junto al agua, sus gritos agoreros y su plumaje blanco y negro levantándose de pronto como un abanico enlutado.

Voy a dedicarle una queja de pidenes y la mancha mojada, como sangre en el pecho, de todas las loicas de Chile.

Voy a dedicarle una espuela de guaso, con rocío matutino, de algún jinete que sale de viaje en la madrugada. por las riberas del Maule y su fragancia.

Voy a dedicarle, levantándola en su honor, la copa de vino de la patria, colmada por las esencias que él describió y gozó.

Vengo a dejarle un rosario amarillo de topatopas, flores de las quebradas, flores salvajes y puras. Pero él también se merece el susurro secreto de los maitenes tutelares y la fronda de la araucana. El, más que nadie es digno de nuestra flora $y^{\prime}$ su verdadera corona está desde hoy en los montes de la Araucanía, tejida con boldos, arrayanes, copihues y laureles.

Una tonada de vendimias lo acompaña y muchas trenzas de nuestras muchachas silvestres, en Ios corredores y bajo los aleros, a la luz del estío o de la lluvia.

$\mathrm{Y}$ esa cinta tricolor que se anuda al cuello de las gui- 
tarras, al hilo de las tonadas, está aquí, ciñe como una guirnalda su cuerpo y lo despide.

Ómos junto a él los pasos de labriegos y de pampinos, de mineros y de pescadores, de los que trabajan, rastrean, socavan, fecundan nuestra tierra dura.

A estas horas está cuajando el cereal y en algún tiempo más los trigales maduros moverán sus olas amarillas en honor del ausente.

De Victoria al sur, hasta las islas verdes, en campos y caseríos, en chozas y caminos, no estará con nosotros, lo echaremos de menos. Las goletas volarán sobre las aguas, cargadas con sus frutos marinos, pero ya Mariano no navegará entre las isilas.

El amó las tierras y las aguas de Chile, las conquistó con paciencia, con sabiduría.y con amor, las selló con sus palabras y con sus ojos azules.

En nuestras Américas, el gobernante, de un clima a otro, no hace sino entregar las riquezas originales. El escritor, acompañando la lucha de los pueblos, defiende y preserva las herencias. Se buscará más tarde si nuestras costumbres y nuestros trajes, nuestras canciones y nuestras guitarras, han sido sacrificados, si ha desaparecido el tesoro que resguardaron hombres como Mariano Latorre, irreductibles en su canto nacional.

Iremos a buscar en la enramada de sus libros, acudiremos a sus páginas preciosas a conocer y defender lo nuestro.

Los clásicos los produce la tierra, o, más bien, la alianza entre sus libros y la tierra, y tal vez hemos vivido junto a nuestro primer clásico Mariano Latorre, sin estimar en lo que tendrá de permanente su fidelidad al mandato de la tierra. Los hombres olvidados, las herramientas y los pájaros, el lenguaje y las fatigas, los animales y las fiestas, seguirán viviendo en la frescura de sus libros.

$\mathrm{Su}$ corazón fue una nave de madera olorosa, salida de los bosques del Maule, bien construida y martillada en los astilleros de la desembocadura y en su viaje por el océano seguirá llevando la fuerza, la flor y la poesía de la patria. 7

Abundante fue también la cantidad de artículos que entregó la prensa chilena a sus lectores. Por encima de los bandos políticos más diametralmente opuestos, los diarios y revisde 1955 .

7 Publicado en El Correo de Valdivia (Valdivia, Chile), 20 de noviembre 
tas, se unieron para rendir un tributo de admiración a don Mariano Latorre. Plumas de reconocido prestigio, Luis Alberto Sánchez, Joaquín Edwards Bello, Hernán Díaz Arrieta (Alone), Manuel Vega, Antonio R. Romera y muchos otros, ${ }^{8}$ se han sumado con interesantes artículos, ensayos y estudios a la ya abundante bibliografía que ha venido estudiando diversos aspectos de la producción de Latorre o procurando elaborar una síntesis interpretativa de lo más distintivo, constante y trascendente del criollismo de Chile en la forma que lo cultivara su más preclaro exponente. De los muchos trozos que pudiéramos seleccionar como muestras de los tributos de la prensa, nos tientan los escritos por Luis Alberto Sánchez en el Zig-Zag y por Joaquín Edwards Bello en La Nacion.

El primero de ellos, sin poder eludir la nota sentimental que a todos los intelectuales comunicó el fallecimiento del autor de On Panta y que se traduce en pintorescos recuerdos y anécdotas, se orienta esforzadamente a sintetizar en breves trazos lo esencial de los relatos de Latorre. Sánchez insiste en conceptos por él ya expresados: Latorre es uno de esos escritores a quienes se debe juzgar en perspectiva. La realidad con que se encarnizó se halla demasiado a la mano. Su procedimiento de la más pura cepa naturalista lindaba con lo judicial.

8 Algunas de las publicaciones más importantes aparecidas en Santiago con motivo de la muerte de don Mariano Latorre son las siguientes: Falleció en Santiago el conocido escritor don Mariano Latorre, El Mercurio, 11 de noviembre de 1955; A. R. R. (Antonio R. Romera), Mariano Lattorre, El Mercurio, 11 de noviembre de 1955; Falleció el escritor don Mariano Latorre, El Diario Ilustrado, 11 de noviembre de 1955; L. G., Poncbo negro por Mariano Latorre, El Diario Ilustrado, 11 de noviembre de 1955; M. V. (Manuel Vega), Mariano Latorre, novelista de Chile, El Diario Ilustrado, 11 de noviembre de 1955; Mariano Latorre, novelista del campo cbileno, falleció ayer, La Nación, 11 de noviembre de 1955; B. (Joaquín Edwards Bello), Notas del Día. Adiós a Mariano, La Nación, 11 de noviembre de 1955; Solemne manifestación de pesar constituyeron los funerales del escritor don Mariano Latorre C., El Mercurio, 12 de noviembre de 1955; $D$. Mariano Latorre se despidió escribiendo. Entregó leyenda de Cbiloé, Ercilla, 15 de noviembre de 1955; El paisaje cbileno enmudeció con la muerte de Mariano Latorre; eva el padre del criollismo, Vea, 16 de noviembre de 1955; Alone (Hernán Díaz Arrieta), Los libros, sobre: La isla de los pájaros, Zig-Zag, 19 de noviembre de 1955; Luis Alberto Sánchez, Mariano Latorre, Zig-Zag, 26 de noviembre de 1955; Mariano Latorre, Atenea (Concepción, Chile), 1955, XXXII, Nov. $365-$ 366, págs. 7-11 y 164-165. 
Así se lo han dicho y así se han burlado y así lo han elogiado. Como era poco sentimental, sus relaciones destilan hechos. Los hechos requieren una doble realidad: la externa y la interna. Luis Alberto Sánchez ya le había dicho esto mismo a Latorre al prologar en 1935 la primera edición de On Panta y re. ferirse al cuento Los aguiluchos. Es decir, Sánchez cree que los hechos son lo que parecen y lo que realmente son: la rea. lidad y su eco:

Latorre a menudo prefería la externa, la apariencia, el eco, pero la interpretaba tan acertadamente, la conocía tan a maravilla, y se estaba consagrando con tanta eficacia a la expresión cabal, pulquérrima, marmórea, que, dentro de un estilo sombrío, castigado y hasta a ratos asmático, ofrecía cuadritos admirables que no se olvidarán y que, ahí la clave del mañana, resucitarán sin tregua ante los ojos de los venideros. De haber duda, bastaría mencionar que Latorre ha dejado discípulos y que esos discípulos no son secuaces incondicionales, sino transformadores $y^{y}$ superadores de la fórmula original del maestro. 9

El último tributo que se hace necesario mencionar es el de don Joaquín Edwards Bello, cronista emotivo y hasta apasionado, pero pintoresco y diestro en el manejo del estilo lingüístico que mejor se acomoda a la labor periodística a que se ha entregado en estos últimos años. ${ }^{10} \mathrm{El}$ sentimiento que vierte en los artículos con que deleita al público de Chile desde las páginas de La Nación de Santiago se deja ver claramente en la crónica que hemos querido reproducir como muestra de un estilo de querer a Latorre, como persona y a Latorre, como escritor :

Esta tarde, desde el tren, venía mirando tu tierra, tu paisaje, tus cordilleras. Todo estaba alegre, lleno de luz tibia. Los pájaros, zorzales, tencas, y diucas, volaban en alada ronda. Un rancho - $i$ e de On Panta?- se derrumbaba bajo e peso de unas viejísimas y aportilladas cala-

9 Luis Alberto Sánchez, Mariano Latorre, trabajo citado en la nota 8.

10 Tal nos ha parecido la personalidad de don Joaquin Edwards Bello, al entrevistarlo en noviembre de 1955, y su estilo al seguir sus crónicas publicadas periódicamente en La Nación de Santiago de Chile. 
minas, sujetas o aplastadas por unas grandes piedras. Unos chiquillos semidesnudos se entretenían, sumiéndose en las aguas de un canal. Todo era igual, lo mismo que todos los días, que todas estas tardes. Nada, nadie, ni las cosas animadas ni las inanimadas sabían que tú te habías muerto. Yo sí que lo sabía, lo venía sabiendo desde una hora fatal y lúgubre. Por eso me sorprendía que la naturaleza, la tuya, no estuviera vestida de luto. El tren no detenía su marcha. Es que nada se detiene, nada se puede detener. Donde una gota de agua pasa, pasa por allí el torrente. Tú mismo no te detuviste jamás en tu ansia nunca satisfecha de creación. ¿Recuerdas aquella noche de invierno en que el cuarto en que abrigamos nuestros sueños quedó lleno de humo? Cuando tú partiste, con aquel otro amigo poeta que ya tampoco es, yo cogí una pluma y un pedacito de papel. En él puse: "Se acaba de ir Mariano. Me he quedado solo en esta pieza. El cuento que nos acaba de leer me ha producido envidia. ¿Podré yo algún día llegar a escribir como él? Mariano tiene grandes pretensiones en literatura. Va a llegar lejos. Y esa fe en sí mismo. Es valiente y yo siento que soy' demasiado cobarde..." Esto fue en 1908, en una fría noche de invierno. Todo nuestro yantar consistió en unas galletas de anís y una botella de vino añejo.

¿Después? ¡Ah, después vino la vida, la que tú desde hoy ya no tienes! La tuya fue una hermosa vida, en la que lograste realizar todo lo que de adolescente quisiste. No tenías interés en hablar del porvenir, porque ya lo sabías hecho a tu medida. Quisiste, trataste de poner belleza hasta donde no la había. Fuiste creador de un nuevo mundo e hiciste hablar con filosofía al labriego más cazurro. Te metiste a luchar con los cóndores, los zorros y los hombres. ¿Quién sabía antes de ti cómo era "El Choroy de Oro?" Nadie sino tú podía encontrar a "Zurzulita". Hablaste como el viento, con los pájaros $\mathrm{y}^{\prime}$ con los elementos. Hiciste de Chile lo que tú querías que fuera no lo que otros habrían querido. Por eso tu criollismo era de buena ley, sano, puro como un joven roble.

¿Por qué te fuiste tan temprano? Todavía quedaba sol para una nueva aurora. Tenías aún la paleta llena de colores y los pinceles estaban al lado de unas rosas. Yo no te podré ver, sino en plena juventud, con tu erguido y rubio mostacho de mosquetero. ¿Te acuerdas? Conviene que hablemos de estas cosas, hoy más que nunca. ¿Cómo hablabas esa tarde en "La Playa", de San Vicente, mientras el gordo Durand reía con toda la mole de su alma y 
de su cuerpo. Estaba también Ricardo, ese taladrante Ricardo con quien nunca dejaste de discutir asuntos sin trascendencia. Y allí el mar, a manera del Coro griego de Esquilo. ¿Te habrás encontrado ya con el gordo Durand? Les veo a los dos, navegando por el piélago, hilvanando cuentos para entretener a las estrellas. Porque aquí como allá has de ser siempre el mismo.

Pero es preciso decirte adiós por breve tiempo. Tú solo sabes cómo te siento vivir en estos momentos en que nada debería decirse. Mientras miraba desde el tren, hace un rato, tu paisaje, tu tierra y tu cielo, hablé contigo largamente. Ya seguiremos hablando por una eternidad. 11

Así despidió la patria chilena a uno de sus hijos predilectos. Sus portavoces, periodistas, eruditos, poetas, novelistas. funcionarios administrativos dejaron oír su voz en el momento de la sepultación o dieron plena libertad a su pluma para que expresara su pensar o su sentir: discretamente como correspondía a la investidura de un crítico parco y objetivo en sus ob. servaciones, emotivo y nervioso en consonancia con el estilo y modo de ser del cronista no sujeto a restricciones, sentido pern mesurado dentro de los límites de originalidad y hermosura que exige la poesía a un vate de fama. A ellos quisiéramos agregarnos los que lejos de Chile estábamos con Mariano Latorre en todos los momentos de su vida literaria, si no fuera que, con el correr del tiempo, nuestras manifestaciones bien pudiesen disonar en el concierto de elogios con que se le vio partir de su tierra querida. Lo ya dicho en otras oportunidades, ${ }^{12}$ vaya co. mo apéndice del homenaje de la intelectualidad chilena a uno de sus más ilustres representantes.

\section{Homero Castillo \\ Northwestern University}

11 B. (Joaquín Edwards Bello), Notas del dia, Adiós a Matiano, citado en la nota 8 .

12 Entre los trabajos sobre Latorre publicados recientemente en los Estados Unidos se cuentan los siguientes:

Magda Arce, Mariano Latorre, novelista cbileno contemporáneo, Revista Iberoamericana, 1942, V. núm. 9, págs. 121-130; 1943, VI, núm. 12, 303-334, Mariano Latorre, Hispanic Institute, 1944, citado en la nota 1, contiene Mariano Latorre: Introducción, por Norberto Pinilla, págs. 5-9; Mariano Latorre: Vida y Obra, por 
Magda Arce, págs. 11-43; Mariano Latorre: Bibliografia, por Magda Arce y Sidonia C. Rosenbaum, págs. 45-49; Antología: Risquera vana, Domingo Persona, La muerte del Pampa Viejo, L'olor no más, On Benoist, págs. 51-88. (Este tomo es tirada aparte de la Revista Hispánica Moderna, 1943, IX).

Homero Castillo, Mariano Latorre, Hispania, 1954, XXXVII, 312-316.

Homero Castillo, Constantes bibliográficas en los cuentos de Mariano Latorre, Court, Symposium, citado en la nota 5.

Las siguientes antologías contienen relatos de Latorre: Sturgis E. Leavitt, Tres cuentos sudamericanos, New York, F. S. Crofts and Company, 1935. (Contiene El piloto Oyarzo y El finado Valdés).

E. Herman Hespelt y otros autores, An Antbology of Spanisb American Literature, New York, F. S. Crofts and Company, 1946. (Contiene en el tomo II, El piloto Oyarzo).

James R. Browne, Stories of the Spanish - Speaking World, Boston, Ginn and Company, 1951. (Contiene Una astucia de Juan Sapo). 